\title{
MONITORING OF EROSION PROCESSES DEVELOPMENT WITH THE USE OF ARCHIVAL REMOTE SENSING DATA
}

\author{
I. I. Nugmanov, E. V. Nugmanova, O. V. Luneva, I. Yu. Chernova \\ Kazan (Volga Region) Federal University, Kazan, Russia
}

\begin{abstract}
The goal of the research is to develop components of the method aimed at output of information on relief-forming processes from archival and current remote sensing (RS) data with the use of the latest data-processing technologies, including photogrammetry and geoinformation systems (GIS). The proposed components of the methods are highly informative and economically effective. The object under study is located at the border of two active tectonic structures, the South Tatar arch and Melekesskian depression in the south-eastern part of the East European platform (Fig. 1). Based on the study results, it is confirmed that neotectonic movements in the area under study and its recent geodynamical setting are directly related (Fig. 5). It is demonstrated that the morphometric method can be efficiently applied to predict zones of high geodynamic activity and to determine locations of such zones.
\end{abstract}

Key words: monitoring, erosion process, geodynamics, photogrammetry, geoinformation systems, neotectonics, morphotectonic analysis.

Recommended by Yu.L. Rebetsky

Citation: Nugmanov I.I., Nugmanova E.V., Luneva O.V., Chernova I.Yu. 2013. Monitoring of erosion processes development with the use of archival remote sensing data. Geodynamics \& Tectonophysics 4 (4), 447-459. doi:10.5800/GT-2013-4-4-0112.

\section{МОНИТОРИНГ РАЗВИТИЯ ЭРОЗИОННЫХ ПРОЦЕССОВ С ИСПОЛЬЗОВАНИЕМ АРХИВНЫХ ДАННЫХ ДИСТАНЦИОННОГО ЗОНДИРОВАНИЯ ЗЕМЛИ}

\author{
И. И. Нугманов, Е. В. Нугманова, О.В.Лунева, И. Ю. Чернова \\ Казанский (Приволжский) федеральный университет, Казань, Россия
}

Аннотация: Целью исследований являлась разработка элементов методики извлечения информации о рельефообразующих процессах из архивных и современных данных дистанционного зондирования (ДЗ) с использованием новейших технологий обработки данных ДЗ, в том числе фотограмметрии и геоинформационных систем (ГИС). Показана высокая информативность и экономическая выгода предложенных элементов методики. Объект исследования расположен на юго-востоке Восточно-Европейской платформы на границе двух активных тектонических структур Южно-Татарского свода и Мелекесской впадины (рис. 1). Результаты исследования подтверждают существование непосредственной связи между неотектоническими движениями и современной геодинамической обстановкой недр исследуемой территорий (рис. 5). В статье показана информативность морфометрического метода для прогнозирования и локализации зон высокой геодинамической активности.

Ключевые слова: мониторинг, эрозионные процессы, геодинамика, фотограмметрия, геоинформационные системы, неотектоника, морфоструктурный анализ. 


\section{1. ВВЕДЕНИЕ}

В последнее десятилетие мониторинг рельефообразующих процессов является одним из самых динамично развивающихся направлений исследований, связанных с изучением изменчивости окружающей среды. Быстрое развитие данного направления обусловлено появлением новых источников данных ДЗ и новых технологий обработки пространственных данных. Другая причина состоит в том, что мониторинг изменения форм рельефа, эрозионных, карстовых, оползневых и других ландшафтообразующих процессов является необходимым условием успешного решения задач долгосрочного планирования и обеспечения устойчивого развития густонаселенных регионов с развитой аграрной и/или промышленной инфраструктурой. Известны успешные проекты по мониторингу состояния земной поверхности на территориях крупных месторождений нефти (по данным радиолокационной съемки) [Filatov, 2006], по выявлению зон активных вертикальных движений в пределах урбанизированных территорий (по данным повторного нивелирования) [Tratsevskaya, Abramovich, 2008], по выявлению процессов разрушения техногенных объектов и ландшафтов (по результатам воздушного и наземного лазерного сканирования и цифровой аэрофотосъемки) [Solutions. Monitoring. Emergencies, 2012] и др. Перечисленные проекты использовали данные и методики, предназначенные для изучения процессов, исчисляемых годами и месяцами, т.е. время действия процессов было соизмеримо с длительностью самого процесса наблюдения, что в полной мере соответствует определению термина «современная геодинамика» [Kuz'min, Zhukov, 2004]. Между тем архивные данные (аэрофото- и космоснимки) прошлого века мы можем ныне рассматривать как весьма ценный материал, позволяющий нам проводить сравнения и изучать тенденции развития рельефа за более длительные периоды времени, использовать рельеф поверхности и связанные с ним ландшафты в качестве комплексных и весьма чувствительных индикаторов проявлений современной геодинамики. Здесь следует отметить, что авторы используют понятие геодинамики, рассматривая его в объеме экзогенной геодинамики, предметом изучения которой являются процессы, происходящие на поверхности Земли под воздействием агентов внешней среды и генетически связанные с движениями и деформациями блоков земной коры [Petrov, 2010; Krasny et al., 2004].

Для авторов наибольший интерес представляет возможность исследования проявлений современной геодинамики в пределах нефтегазоносных регионов. Перед нами стоит задача изучения влияния геодинамических процессов и связанных с ними неотектонических движений недавнего геологического прошлого (до $10^{6}$ лет) на образование скоплений углеводородов и их устойчивость во времени, что является проблемой практически неизученной. Однако в процессе изуче- ния материала и разработки методики выявления и анализа рельефообразующих процессов обнаружилось, что предложенный подход к изучению архивных данных может быть использован при решении широкого круга практических задач и научных проблем.

\section{2. МЕТОДИКА ИССЛЕДОВАНИЙ И НОВЫЕ ПРИЕМЫ АНАЛИЗА}

Одна из основных задач настоящего исследования состояла в получении новых сведений о процессах, формирующих рельеф и ландшафты, а также в развитии новых методик извлечения информации о геодинамических процессах из данных дистанционного зондирования. Авторы предлагают использовать комплексную методику, включающую методы качественной и количественной оценки деформаций верхней части земной коры по данным архивной и исторической аэрофото- и космосъемки, а также метод создания карт и схем неотектонической активности. Сравнение качественных и количественных характеристик движений земной коры за разные промежутки времени (от 10 до 1 млн лет) позволит приблизиться к решению вопроса о характере взаимосвязи современных геодинамических явлений и неотектонических процессов.

В качестве программного обеспечения проекта были выбраны: программа-векторизатор EASY TRACE PRO 8.7 (EASY TRACE GROUP, Россия), географическая информационная система ArcGIS 10 (ESRI, США), программа обработки данных дистанционного зондирования ERDAS Imagine 2010 (ERDAS, США).

Методы обработки аэрофотоснимков 1953 и 1980 гг. сводились к подгонке планового изображения снимков к изображению мозаики WorldView, т.е. к их геометрической коррекции и определению системы координат. Геометрическая коррекция выполнялась в модуле IMAGINE AutoSync, средняя ошибка трансформации составила 6.5 м. Далее трансформированные изображения загружались в геоинформационный проект для визуального сравнения и анализа разновременных изображений аэрофотоснимков и космоснимков в плане. Более подробно методика обработки коллекции архивных аэрофотоснимков изложена в работе [Chernova et al., 2010a].

Для создания карт и схем неотектонических движений был использован морфометрический метод анализа цифровых моделей рельефа (ЦМР). Этот метод впервые был предложен С.С. Соболевым (1948 г.). Позднее метод был развит В.П. Философовым и другими исследователями [Filosofov, 1975; Lastochkin, 1971], применявшими его к поискам перспективных нефтегазоносных локальных поднятий. Морфометрический метод интересен тем, что дает представление о неотектоническом режиме исследуемой территории по всей площади исследования, что для геоморфологических и инструментальных методов 


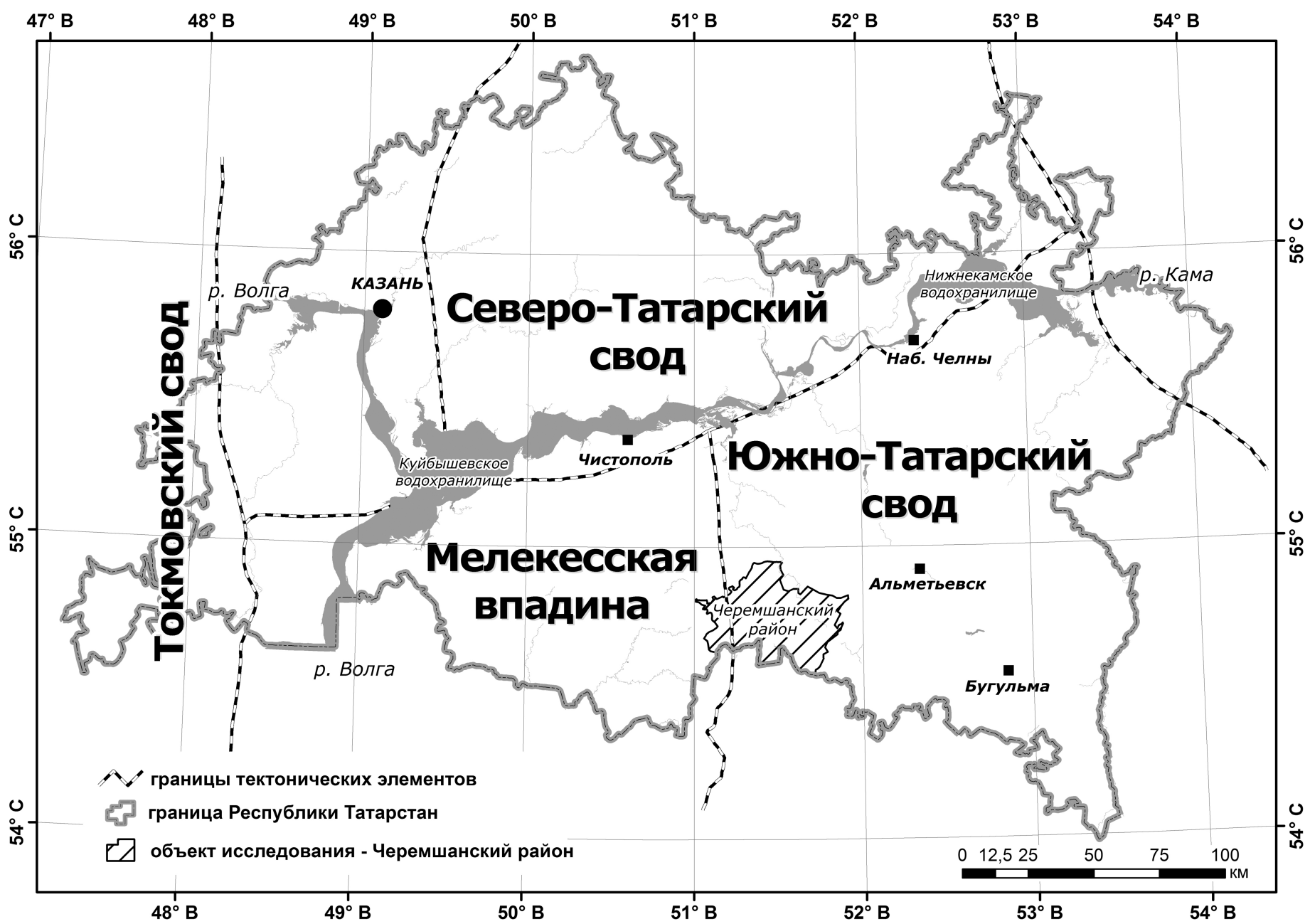

Рис. 1. Географическое местоположение объекта исследования.

Fig. 1. The geographical location of the object under study.

изучения неотектоники большая редкость (в основном исследователям приходится довольствоваться точечными наблюдениями или наблюдениями вдоль профилей). Морфометрический метод основан на предположении о том, что движения земной коры, взаимодействуя с экзогенными процессами, преодолевают их выравнивающую деятельность и находят, в конечном счете, свое отражение в современном рельефе и характере речной сети. При выполнении морфометрического анализа рельеф раскладывается на компоненты (уровни, или морфометрические поверхности разных порядков), каждая из которых соответствует определенному этапу неотектонической истории и отображает неотектонические структуры разного порядка: от региональных до локальных. Таким образом, мы можем восстановить историю развития рельефа от современного периода до начала неотектонического. Или наоборот. А если будем вычитать один уровень из другого, то получим серию разностных поверхностей, которые показывают степень активности неотектонических структур за определенный период тектониче- ского развития региона, давая при этом количественные оценки амплитуд и направлений вертикальных движений. Подробно реализация морфометрического метода с использованием инструментария геоинформационной системы (ГИС) изложена в работе [Chernova, 2010b].

\section{3. ОБЪЕКТ ИССЛЕДОВАНИЯ И ФАКТИЧЕСКИЕ ДАННЫЕ}

В качестве объекта исследования была выбрана территория Черемшанского района Республики Татарстан (РТ) - территория с весьма развитой аграрной инфраструктурой, с интенсивной добычей нефти. С точки зрения изучения современной геодинамики данная территория является привлекательным объектом, так как находится на границе двух активных тектонических структур I порядка - Южно-Татарского свода и Мелекесской впадины (рис. 1). Разнообразные формы рельефа, наличие крупных рек и множества мелких водотоков дают основание предполагать, что искомые 


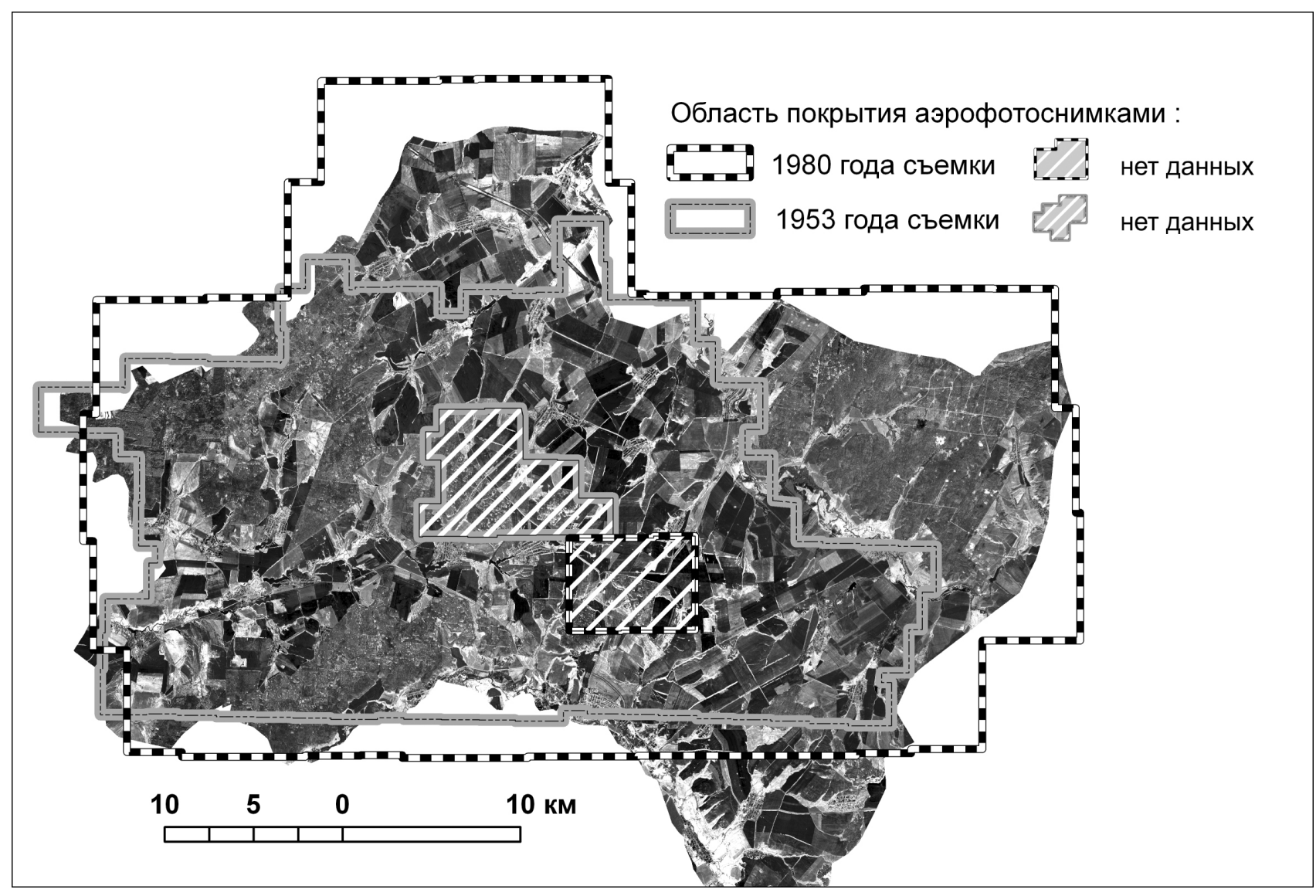

Рис. 2. Объект исследования - территория Черемшанского района РТ.

Растровая подложка рисунка представлена мозаикой снимков WorldView.

Fig. 2. The territory of Cheremshansky district of the Tatarstan Republic as the object under study.

Background: WorldView-1 satellite imagery mosaic.

проявления современной геодинамики будут обнаружены, а современные формы рельефа имеют неотектоническое происхождение.

На выбор территории исследования также повлияло наличие достаточного количества исходного материала. В проекте были использованы данные аэрофотосъемки территории РТ 1953 г. (масштаб съемки 1:17000, высота полета 1100 м) -186 снимков, данные аэрофотосъемки 1980 г. (масштаб съемки 1:50000, высота полета 7000 м) - 65, а также данные съемки 2008 г. со спутника WorldView (панхроматический диапазон съемки, пространственное разрешение 60 см) - 19 сцен (рис. 2). Все архивные данные были предоставлены библиотечным фондом Казанского федерального университета.

\section{4. СРАВНИТЕЛЬНЫЙ АНАЛИЗ РАЗНОВРЕМЕННЫХ ДАННЫХ ДИСТАНЦИОННОГО ЗОНДИРОВАНИЯ}

При сравнении разновременных данных обнаружилось, что за 55 лет рельеф и ландшафт территории мо- гут претерпевать существенные изменения. Часть изменений имеет явно техногенное происхождение (строительство плотин, запруд, каналов, перенос русла реки). Другие изменения можно почти уверенно отнести к проявлениям современной геодинамики. Известно, что если территория испытывает восходящие движения, то ее ландшафт и формы рельефа приобретают специфические очертания [Filosofov, 1975; Lastochkin, 1971]: возрастают абсолютные отметки высот, русла рек и других водотоков спрямляются или приобретают резкие повороты (вплоть до 90), объем выносимого материала увеличивается, стремительно развивается овражная сеть (увеличивается глубина и линейные размеры оврагов, промоины быстро превращаются в овраги). В случае тектонического опускания территории эрозионные процессы затухают, овраги зарастают, мелкие постоянные и временные водотоки исчезают, а крупные начинают меандрировать.

На исследуемой территории мы обнаружили все перечисленные признаки проявления современных геодинамических процессов. С этой точки зрения интересно рассмотреть историю развития овражно-ба- 

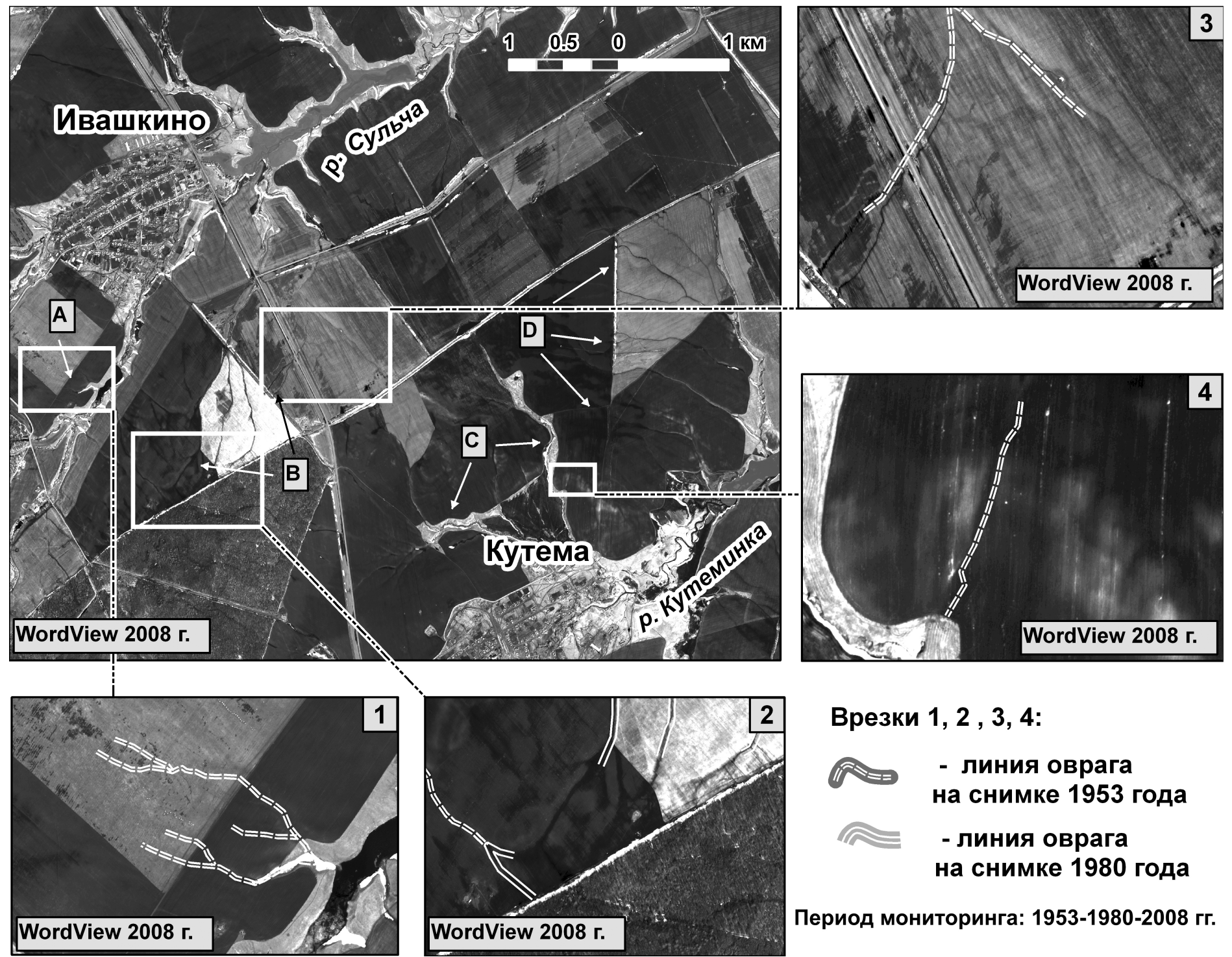

Врезки 1, 2, 3, 4:

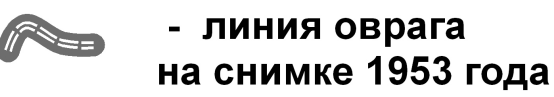

\section{- линия оврага на снимке 1980 года}

Период мониторинга: 1953-1980-2008 гг.

Рис. 3. Сравнение архивных и современных данных: выявление признаков развития эрозионных сетей.

Fig. 3. Comparison of archival and current data in search for erosion development indicators.

лочных сетей вблизи поселков Ивашкино и Кутема (рис. 3), которые мы условно назвали сети A, B, C и D. Сети А и В относятся к бассейну реки Сульча, сети C и $\mathrm{D}$ впадают в р. Кутеминка, русло которой соединяется с руслом реки Сульча за пределами рассматриваемого участка. Несмотря на то, что сети А и В относятся к бассейну одной реки, развивались они по-разному. К 1953 г. овраги А и В уже достигли длины 1.5-2.0 км и имели сеть отвершков. По-видимому, сети находились в стадии активного роста и создавали большие проблемы для ведения сельского хозяйства. В связи с этим в период между 1953 и 1980 гг. на реке Сульча была построена запруда вблизи поселка Ивашкино. Ожидалось, что развитие овражных сетей прекратится, но реакция сетей оврагов оказалась различной. Несмотря на близость запруды, отвершки овражной сети В продолжили свое развитие. На врезке 3 рисунка 3 показан рост оврагов за период с 1953 по 2008 г. (средняя скорость роста не менее 7 м/год), на врезке 2 - за период с 1980 по 2008 г. (средняя скорость роста 8-9 м/год). На врезке 2 видно, что в период с 1980 по 2008 г. овраги пересекли поля и «врезались» в лесной массив: на снимках 2008 г. линии оврагов видны очень хорошо, на снимках 1953 и 1980 гг. лесной покров выглядит ненарушенным. Для овражной сети А сравнение данных показало, что в период с 1953 по 2008 г. овраги длиной 300-500 м деградировали: на снимке 2008 г. видно, что их долины распаханы, а в рельефе они проявляются лишь как небольшие понижения (врезка 1 рис. 3).

Для овражной сети D сравнение данных показало, что эта сеть за наблюдаемый период времени существенных изменений не претерпевала. Возможно, что установление устойчивого состояния эрозионной сети 
было обусловлено строительством запруды вблизи поселка Кутема. Запруда была построена после 1980 г., но и до строительства ни форма, ни длина ветвей оврагов не изменялись.

В наблюдаемый период времени сеть С явно деградировала: отвершки исчезли (врезка 4 рис. 3), а основные овраги окончательно превратились в балки.

Подобные детальные сравнения разновременных данных были выполнены для 246 объектов овражнобалочных сетей на территории Черемшанского района. Для некоторых участков отчетливо установить тенденции развития эрозионных сетей не удалось (например, в лесных массивах уверенно проследить рост овражной сети невозможно). Также часть информации была утеряна из-за низкого качества ряда аэрофотоснимков. Тем не менее удалось сделать ряд интересных наблюдений и выявить десятки участков с проявлениями современной геодинамики как положительного, так и отрицательного знака. 54 объекта овражнобалочных сетей демонстрируют признаки активного роста, 70 - деградации, состояние 122 эрозионных сетей не изменялось.

\section{5. МОРФОМЕТРИЧЕСКИЙ АНАЛИЗ}

Морфометрический анализ представляет собой инструмент для оценки тектонических движений за неоген-четвертичный период. Техническая реализация этого метода (собственно расчет и построение морфометрических поверхностей) в настоящее время не представляет большой проблемы [Chernova, 2010b]. Намного более интересен и важен вопрос интерпретации созданных поверхностей и оценка информативности метода, в частности оценка возраста той или иной поверхности и, следовательно, возможность оценки скоростей вертикальных движений. В данном случае нас интересовали разности базисных поверхностей низших порядков. Базисной поверхностью называют поверхность, объединяющую местные базисы эрозии. Базисные поверхности различают по порядкам в соответствии с порядками долин. Долинами 1-го порядка называются долины, в которые не впадают никакие другие долины, долины 2-го порядка образуются при слиянии двух долин 1-го порядка, долины 3-го порядка образуются при слиянии долин 2-го порядка и т.д. [Filosofov, 1975]. Базисная поверхность 1-го порядка объединяет местные базисы эрозии долин всех порядков, базисная поверхность 2-го порядка объединяет местные базисы эрозии долин 2-3-го и всех более высоких порядков, базисная поверхность 3-го порядка объединяет местные базисы эрозии долин 3-го и всех более высоких порядков и т.д. Базисные поверхности низших порядков незначительно отличаются от дневного рельефа. Если бы тектонические движения отсутствовали, то в начале эрозионного цикла рельеф был бы размыт до базисной поверхности 2-го порядка, за- тем - до поверхности 3-го порядка и т.д. Разности базисных поверхностей 1 и 2-го порядка показывают направленность и интенсивность тектонических движений в период времени между современным и самым поздним этапами истории развития рельефа. Разность базисных поверхностей 1 и 2-го порядка для территории Черемшанского района РТ представлена на рисунке 4. Расчет базисных поверхностей и их разности был выполнен на основе цифровой модели рельефа масштаба 1:200 000 [Chernova, 2010a].

Возраст базисных поверхностей выше 1-го порядка может быть определен только приближенно. Долинами 1-го порядка в равнинных странах являются промоины, рассекающие склоны и ложбины стока, возникающие на водораздельных пространствах. Ложбины стока переходят в овраги или балки, а последние - в реки. В условиях умеренного климата речные долины с постоянным стоком воды обычно имеют 3 или 4-й порядок. В долинах 1 и 2-го порядка протекают лишь временные ручьи. Следует иметь в виду, что часть балок имеет молодой голоценовый возраст.

В связи с этим можно считать, что разность базисных поверхностей 1 и 2-го порядка [Zayonts et al., 1967; Filatov, 1967] показывает направленность и интенсивность тектонических движений, произошедших в период времени между современным и самым поздним этапами истории развития рельефа (не ранее плейстоцена, 1.6 млн лет).

\section{6. ОБСУЖДЕНИЕ РЕЗУЛЬТАТОВ И ВЫВОДЫ}

Вообще говоря, скорость роста оврагов нельзя использовать в качестве прямого признака геодинамической активности исследуемых территорий, так как развитие оврагов является многофакторным процессом, причем на разных этапах развития роль этих факторов может существенно меняться [Dedkov, 1990; Butakov et al., 2000; Chalov, 1989]. Но использовать скорость роста в качестве косвенного признака - вполне обоснованно.

Существует мнение о том, что экзогенные геологические процессы, и в первую очередь те из них, которые происходят под действием поверхностных вод, носят эволюционный характер и не объясняют знакопеременный характер современных суперинтенсивных деформаций земной поверхности [Kuz'min, 1999].

Исследованиями эрозионных процессов на территории Европейской России, и в частности Республики Татарстан [Dedkov et al., 1997; Serebrennikova et al., 1999; Keay-Bright, Boardma, 2009; Parkner et al., 2006], за последние 70 лет установлено, что общая продолжительность «жизни» оврагов в среднем составляет 100-150 лет, после чего они переходят в молодые балки. Считается, что современный этап овражной эрозии спровоцирован хозяйственной деятельностью человека. Получив первоначальный толчок для своего разви- 


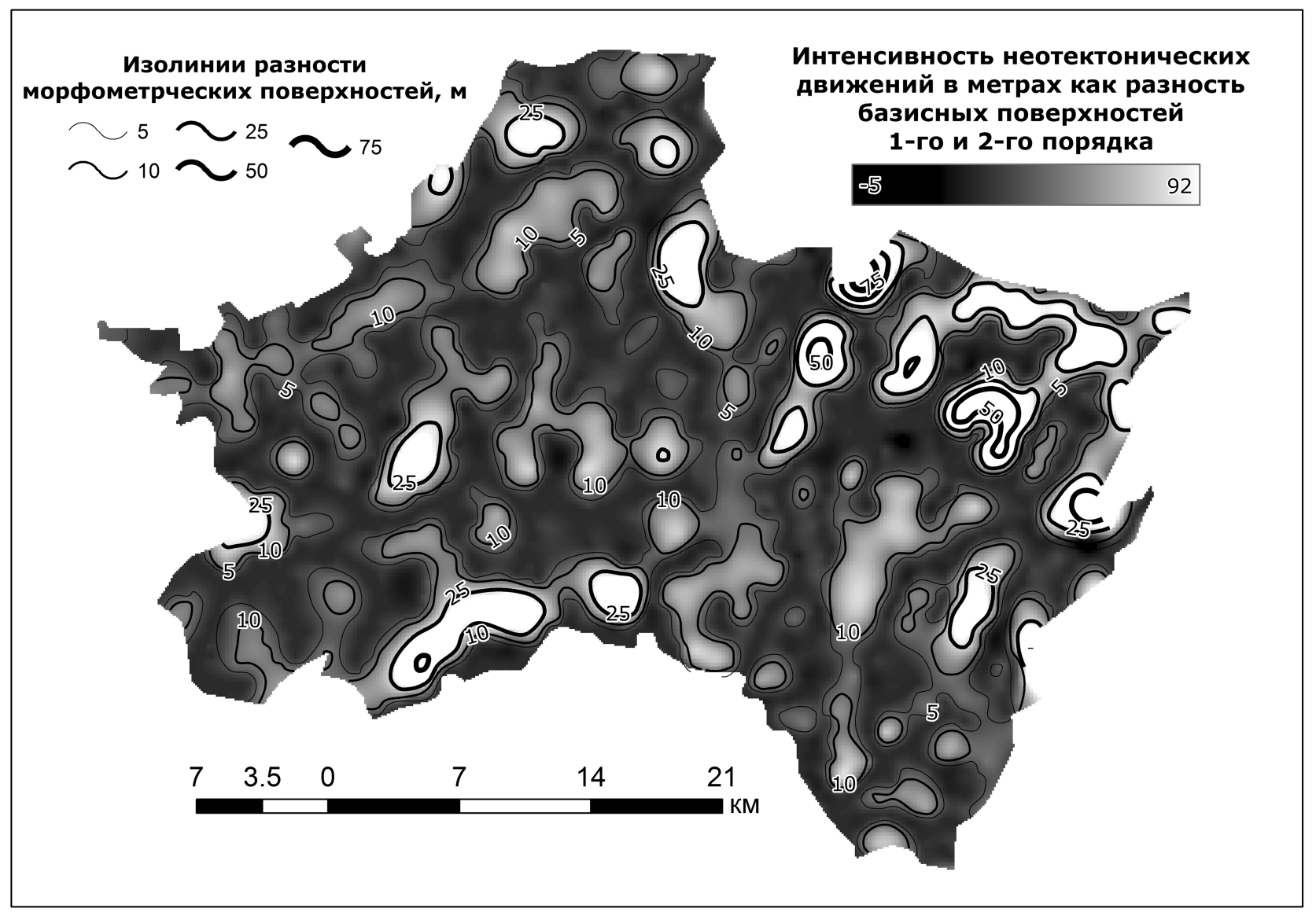

Рис. 4. Разность базисных поверхностей 1 и 2-го порядка.

Fig 4. The difference between the base-level surfaces of the 1st and 2nd orders.

тия, эрозия на начальном этапе развивается весьма стремительно (первые 15-20 лет). Затем при стабильном положении всех факторов, влияющих на рост оврагов, происходит плавное и медленное затухание эрозионного процесса. С другой стороны, в тех же источниках указываются многочисленные примеры отклонения в истории развития оврагов от традиционной стадийности [Dedkov, 1990; Butakov et al., 2000; Parkner et al., 2006]:

- анализ кривых скоростей линейного роста оврагов обнаруживает наличие периодичности (3-5 лет). Пульсационный характер роста оврагов обычно связывается с гидрометеорологическими условиями того или иного рода. Но, в целом, значения показателей связи между отдельными гидрометеорологическими и геоморфологическими факторами не очень высоки [Butakov et al., 2000];

- многие длительно существующие овраги зарастают, замедляют или прекращают свой рост, но возникают новые или развиваются боковые отвершки у старых форм [Dedkov, 1990]; противоэрозионные мероприятия далеко не всегда приводят к желаемому эффекту [Dedkov, 1990; Chalov, 1989]. Помимо многочисленных упоминаний этого факта в литературе, его наглядный пример также приводится и в данной работе;

- современный этап эрозионной активности не является единственным и первым. В геологической истории территории Татарстана (и Русской равнины в целом) были периоды, когда линейная эрозия охватывала более значительные пространства. Доказательством этого являются древние балки, многие из которых заложились в виде оврагов или долин небольших речушек в начале позднего плейстоцена [Dedkov, 1990].

В работе [Dedkov, 1990] также указывается, что в большинстве районов РТ густота балок значительно превышает густоту оврагов. Это, по мнению авторов монографии, свидетельствует о том, что современная эрозия еще не достигла масштабов древней. Также авторы монографии отмечают, что, хотя первичные овраги преобладают над вторичными в два раза и более и современная эрозия в большинстве случаев осваивает новые участки, нет оснований говорить о явной независимости нынешней эрозии от древней. Положение не только вторичных, но и в значительной степени первичных оврагов предопределено реликтовыми формами (часть первичных оврагов закладывается по склонам балок). 


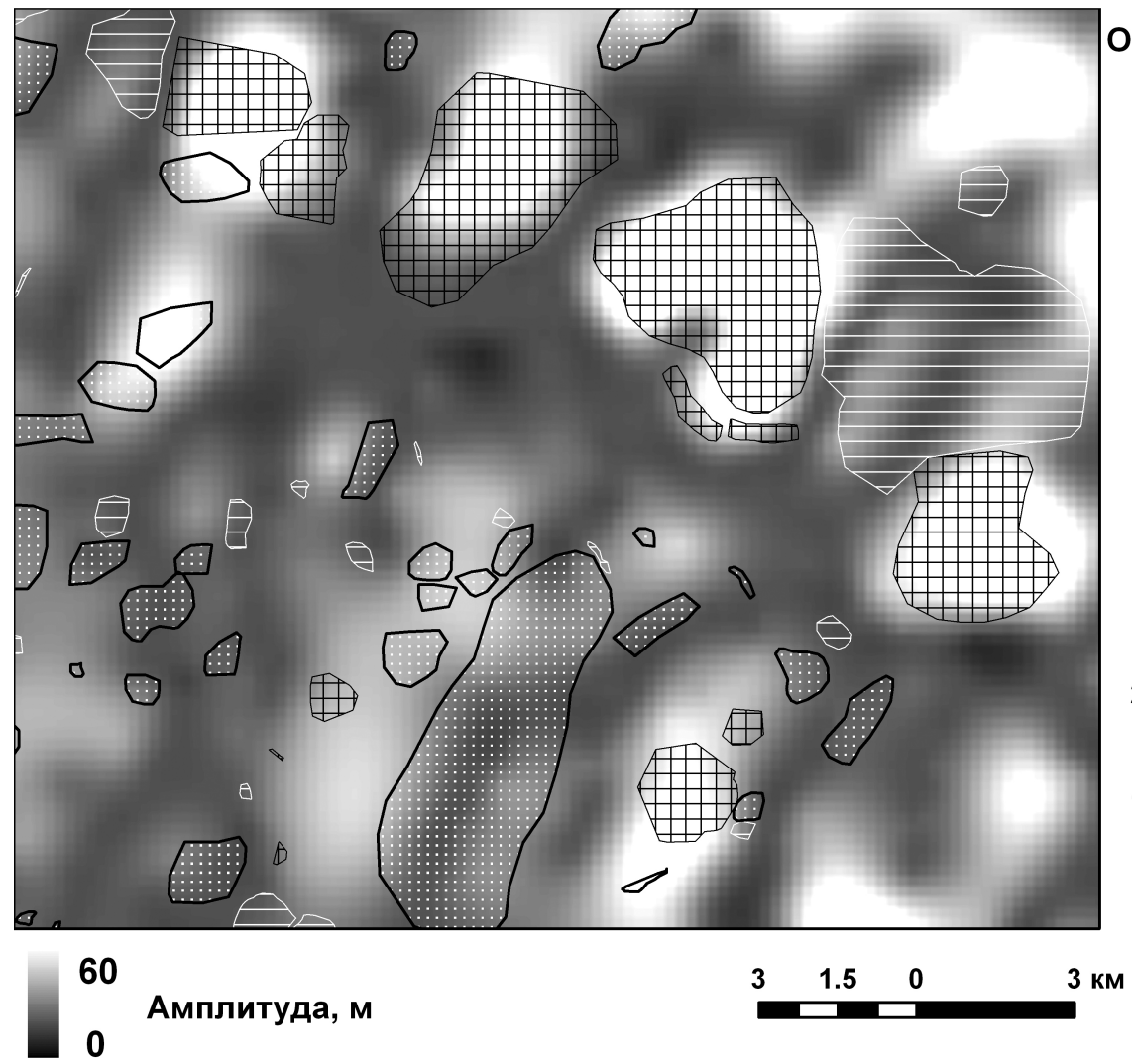

$\sigma$ Области с различными современными
геодинамическими обстановками:

1 - без изменений

2 - с положительной динамикой

3- с отрицательной динамикой

\section{Распределение средних амплитуд по группам}

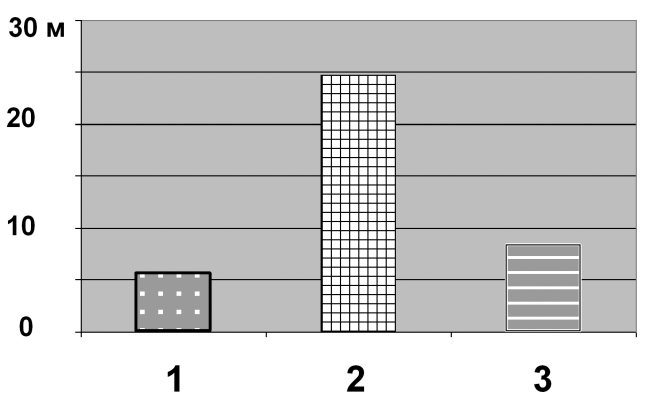

Рис. 5. Сопоставление проявлений современной геодинамики и признаков неотектонической активности в пределах территории исследования.

Fig. 5. Comparison between the recent geodynamics and the neotectonic activity indicators within the area under study.

Вышеперечисленные факты свидетельствуют о том, что жизненный цикл эрозионных сетей помимо «очевидных» факторов (объем водного стока, уклон, состав горных пород, залесенность, интенсивность и продолжительность снеготаяния, распашка земель и др.) контролируется более масштабными процессами, обусловливающими не только эти, но и все другие явления, формирующие лик Земли. К таким масштабным процессам, по мнению авторов, прежде всего, необходимо отнести тектонические события, периодические или событийные, которые в конечном итоге выражаются в вертикальных движениях блоков земной коры и отвечают за формирование высот, уклонов и форм склонов. В поисках причин активизации и затухания эрозионных процессов исследователи изучали зависимость параметров роста оврагов от метеорологических и других показателей. Но, как указывается в работе [Butakov et al., 2000], коэффициенты корреляции в большинстве случаев оказывались невысокими $(<0.5)$, за исключением зависимостей показателей овражности от размываемости грунтов. Натурные наблюдения и результаты моделирования [Chalov, 1989] приводят геоморфологов к выводу, что на интенсивность роста и размеры оврага наибольшее влияние оказывают глу- бина базиса эрозии и форма склона. По данным [Dedkov et al., 1997; Serebrennikova et al., 1999], положительные и отрицательные аномалии роста оврагов в целом хорошо увязываются с аномалиями стока взвешенных наносов на реках Восточно-Европейской платформы, хотя полного соответствия нет [Dedkov et al., 1997]. Но, при прочих равных условиях, скорости потока, изменение его транспортирующей способности также зависят от глубины базиса эрозии и формы склонов. При большой крутизне и большой глубине базиса эрозии верховья оврага могут настолько близко подходить к линии водораздела, что ширина зоны отсутствия эрозии становится исчезающе малой. Конечно, нельзя забывать о естественных колебаниях климата и общей увлажненности, которые, несомненно, вызывают изменения высоты глобального базиса эрозии. Но изменение формы склонов и относительных высот местных базисов эрозии может быть объяснено только с позиции неотектоники.

Соотношение проявлений современной геодинамики и неотектонических движений можно проанализировать, сравнивая результаты анализа развития эрозионных сетей (по данным ДЗ) с результатами морфометрического анализа. На рисунке 5, а, приводится 


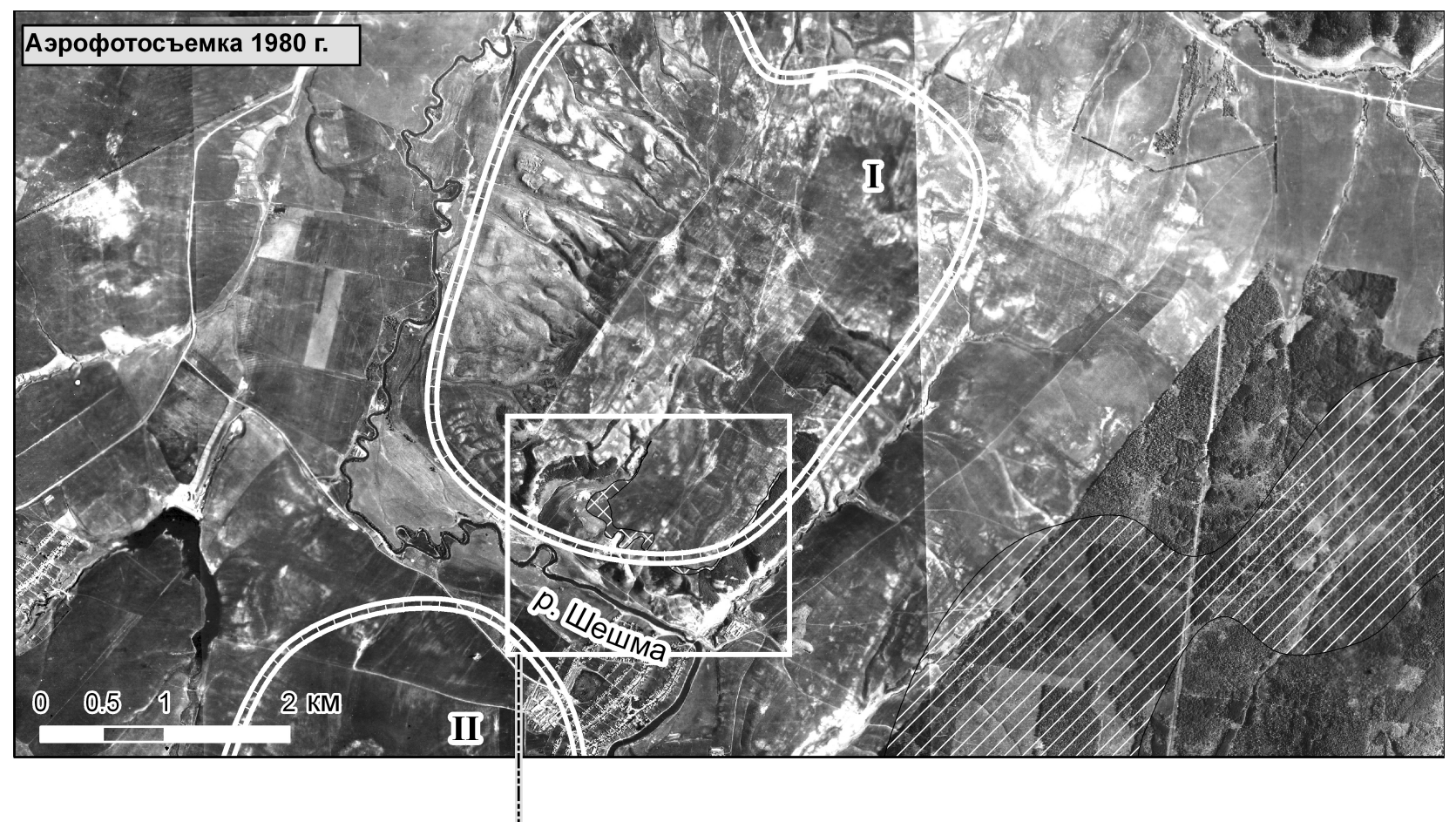

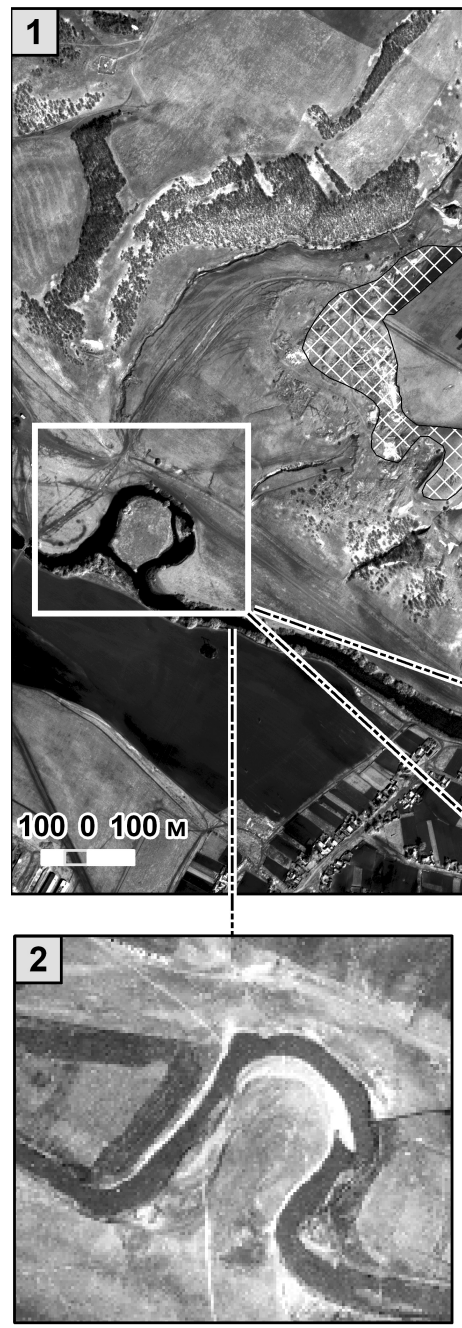

Аэрофотосъемка 1953 г.
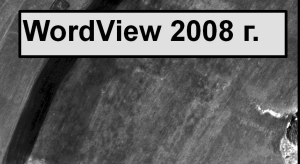

Амплитуда, м

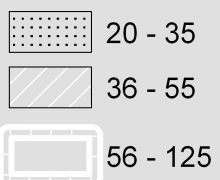

Врезка 1:

\section{Зона интенсивного размыва}

Врезки 2, 3, 4:

прорыв и образование нового русла реки в период c 1953 по 2008 гr.

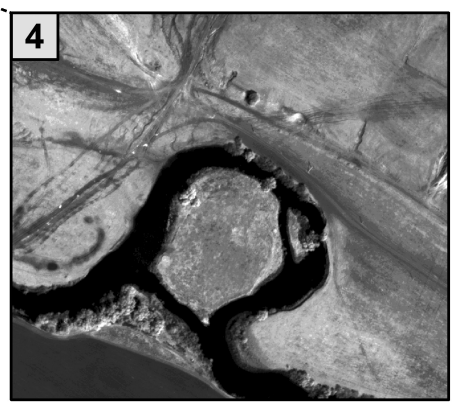

WordView 2008 r.

| Рис. 6. Формирование элементов рельефа и ландшафта под действием неотектонических факторов.

Fig. 6. Formation of components of the relief and the landscape due to neotectonic factors. 


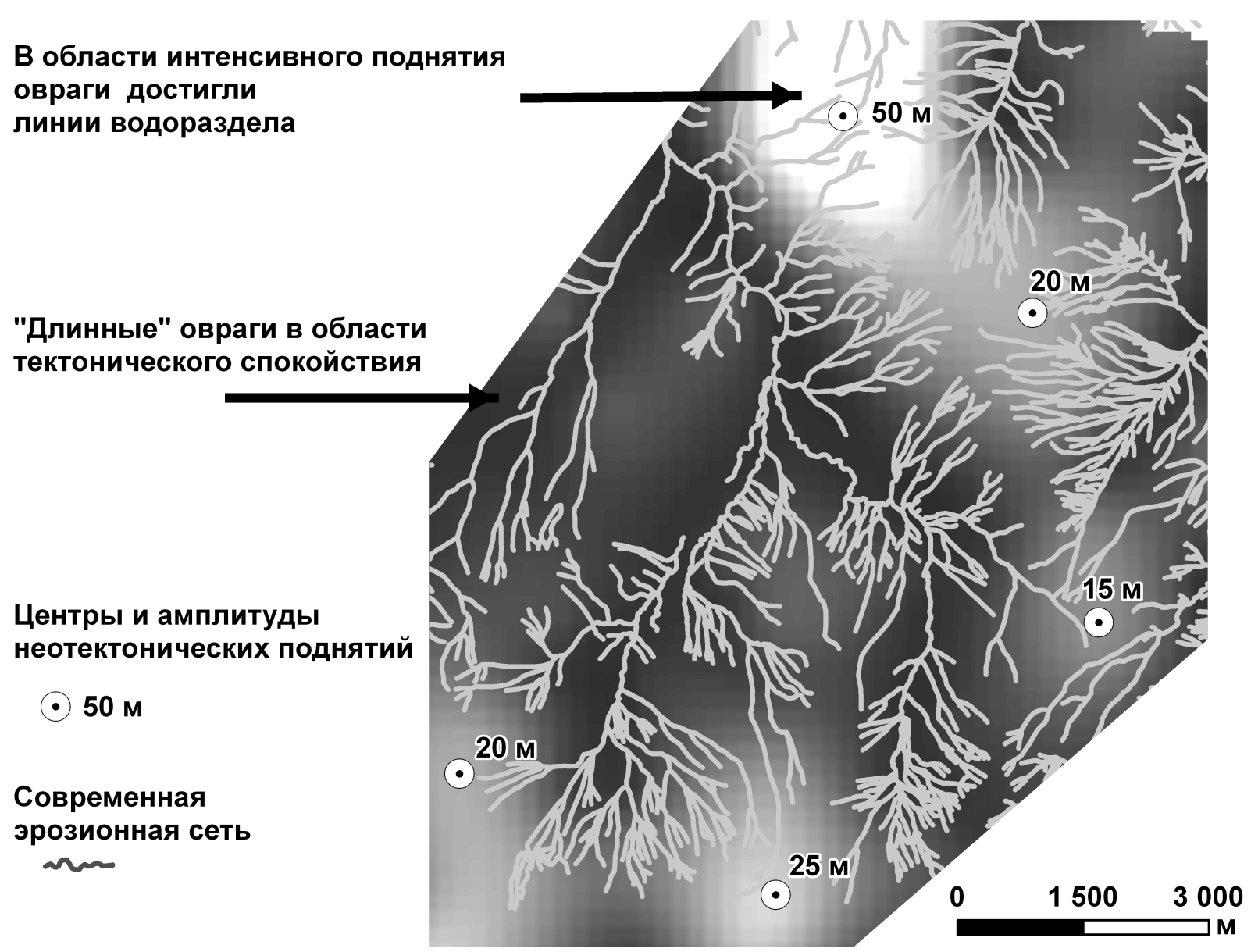

Рис. 7. Особенности развития эрозионных сетей вблизи и на некотором удалении от центров неотектонических поднятий.

Fig. 7. Specific features of development of erosion networks in the vicinity and at a distance from centres of neotectonic uplifts.

фрагмент карты неотектонической активности, созданной для территории Черемшанского района, а также распределение областей проявления современной геодинамической активности по амплитудам новейших вертикальных движений (рис. 5, б). Растровой подложкой рисунка является разность базисных поверхностей 1 и 2-го порядка (см. рис. 4). Как уже указывалось выше, этот вид морфометрической поверхности показывает направленность и интенсивность тектонических движений, произошедших за самые поздние этапы истории развития рельефа. Следовательно, эта поверхность является отражением современной геодинамической обстановки исследуемой территории. Так как поверхность была рассчитана на основе цифровой модели рельефа масштаба 1:200000, представленные на ней неотектонические формы являются региональными для наших более детальных исследований. Диаграмма (рис. 5, б) представляет средние значения амплитуд вертикальных движений в пределах каждого типа полигонов, представляющих области, в которых исследовались верховья оврагов. Очевидно, что существует прямая связь между проявлениями неотектонической активности и проявления- ми современной геодинамики: области деградации или стабильного состояния эрозионной сети приурочены $\mathrm{K}$ областям неотектонического спокойствия, области с положительной динамикой расположены в непосредственной близости к средне- и высокоамплитудным неотектоническим поднятиям.

На рисунках 6 и 7 показаны еще несколько ярких примеров взаимосвязи проявлений современной геодинамики и неотектоники. На аэрофотоснимок 1980 г. наложены контуры высокоамплитудных неотектонических поднятий (см. рис. 6). На снимке видно, что поднятие I лишено лесной растительности и почти полностью изрыто эрозионными формами по типу бедленда. На врезке 1 наблюдаем процесс спрямления русла реки (врезки 2, 3, 4 рис. 6). На снимке (и на стереопаре) видно, что на этом участке оба берега Шешмы очень крутые.

На рисунке 7 показан фрагмент современной эрозионной сети, оцифрованной по данным ДЗ. Видно, что рисунок сети определяется не столько абсолютными отметками высот, сколько распределением центров неотектонических поднятий. Поднимающимся участкам соответствует большая густота эрозионной сети, 
центробежный или радиальный план долинной сети, относительное уменьшение длины долин (короткие овраги). В пределах тектонических впадин нарастание порядков долин идет медленно, длина долин значительно увеличивается. Мы наблюдаем, как образуются «длинные» овраги: долины оврагов и балок тянутся через области неотектонического спокойствия к центрам неотектонических поднятий. Здесь мы наблюдаем классическое поведение эрозионных сетей, многократно описанное геоморфологами, изучающими неотектонические факторы формирования рельефа [Zayonts et al., 1967; Filatov, 1967; Lastochkin, 1971]. Геоморфологи, изучающие стадийность и экзогенные факторы развития эрозионных сетей, неотектонический фактор не рассматривают [Dedkov, 1990; Butakov et al., 2000; Chalov, 1989].

Таким образом, наши исследования подтверждают существование непосредственной связи между проявлениями современной геодинамики и неотектоническими движениями. Давно известно, что морфометрический анализ дает хорошую «отдачу» при использовании на платформах, где позволяет выявлять пологие погребенные поднятия, слабо отражающиеся в рельефе. Но сейчас нам стал более понятен геологический смысл разности базисных поверхностей низших порядков. Если наложить линии водотоков 1 и 2-го порядка (в нашем случае полученные в результате моделирования на основе ЦМР масштаба 1:200000) на аэрофотоснимки, то легко определить, что смоделированные водотоки 2-го порядка по форме и высотному положению соответствуют долинам современных оврагов и балок, а водотоки 1-го порядка - наиболее крупным отвершкам оврагов. Из этого следует, что возраст базисной поверхности 1-го порядка мы можем принять как $\sim 10^{2}$ лет, а возраст базисной поверхности 2-го порядка - как позднеплейстоценовый ( $10^{4}$ лет). Следовательно, временной интервал, в течение которого образовалась базисная поверхность 2-го порядка, мы может оценить как $\sim 10^{4}$ лет. Средняя и максимальная оценки амплитуд поднятий на разности базисных поверхностей 1 и 2-го порядка составляют $\approx 10$ и 100 м, соответственно. Из этого следует, что средние скорости современных движений оцениваются в $\sim 1$ мм/год, а максимальные - в $10 \mathrm{mм} /$ год, что не противоречит инструментальным измерениям на платформах [Niconov, 2006; Trifonov, 1999].

Таким образом, разность базисных поверхностей низших порядков мы можем использовать в качестве достаточно надежного источника информации о современном геодинамическом состоянии исследуемых территорий. Если использовать в качестве исходных данных топокарты или ЦМР более крупных масштабов, можно получать более детальные неотектонические схемы, с помощью которых мы можем локализовать зоны высокой геодинамической активности, выявить геологические (тектонические) предпосылки для возникновения опасных или негативных для развития ландшафтов явлений: от потери почв и сокращения площадей сельхозугодий до возникновения природнотехногенных ЧП (аварии на трубопроводах, разрушение зданий, дорог, мостов, промышленных сооружений).

\section{7. ЗАКЛЮЧЕНИЕ}

Методические приемы, описанные выше, могут быть применены для любых участков платформенных областей с развитыми эрозионными сетями. Основным преимуществом данной методики является площадное представление результатов анализа. Было бы интересно получить подобные результаты и для других участков платформ. Больший объем накопленной информации позволил бы с большей уверенностью говорить о характере взаимосвязи между процессами современной геодинамики и неотектоники, которая, по мнению авторов, определенно существует.

\section{8. БЛАГОДАРНОСТИ}

Авторы глубоко признательны заведующему лабораторией тектонофизики им. М.В. Гзовского ИФЗ РАН Ю.Л. Ребецкому за внимание к данным результатам, первоначально представленным на одной из секций III Тектонофизической конференции в ИФЗ РАН «Тектонофизика и актуальные вопросы наук о Земле» (Москва, 8-12 октября 2012 г.), и предложение опубликовать их в журнале. Авторы благодарны рецензентам работы за проведенный анализ и ценные замечания, которые, несомненно, способствовали улучшению статьи.

Работа выполнена при финансовой поддержке ФЦП «Научные и научно-педагогические кадры инновационной России на 2009-2013 г.», ГК № 14.A18.21.0610, № 14.A18.21.0687, и Министерства образования и науки РФ (проект № 02.G25.31.0029).

This work is supported by the German-Russian Interdisciplinary Science Center (G-RISC) funded by the German Federal Foreign Office via the German Academic Exchange Service (DAAD).

\section{9. ЛИТЕРАTУРA / REFERENCES}

Butakov G.P., Zorina E.F., Nikolskaya I.I., Rysin I.I., Serebrennikova I.A., Yusupova V.V., 2000. Trends in development of gully erosion in European Russia. In: Erosion and channel processes. Moscow State University, Moscow, Issue 3, p. 52 62 (in Russian) [Бутаков Г.П., Зорина Е.Ф., Никольская И.И., Рысин И.И., Серебренникова И.А., Юсупова В.В. 
Тенденции развития овражной эрозии в Европейской России // Эрозионные и русловые процессы. М.: МГУ, 2000. Вып. 3. С. 52-62].

Chalov R.S. (Ed.), 1989. Gully Erosion. Publishing House of Moscow State University, Moscow, 168 p. (in Russian) [Oвражная эрозия / Под ред. Р.С. Чалова. М.: Изд-во МГУ, 1989. 168 с.].

Chernova I.Yu., Nugmanov I.I., Dautov A.N., 2010a. Application of GIS analytic functions for improvement and development of the structural morphological methods of the neotectonics studies. Geoinformatika 4, 9-23.

Chernova I.Yu., Nugmanov I.I., Dautov A.N., Krylov P.S., 2010b. Monitoring of relief-forming processes by photogrammetry and GIS. Bulletin of the Samara Scientific Center RAS 12 (33), 1 (4), 1170-1176 (in Russian) [Чернова И.Ю., Нугманов И.И., Даутов А.Н., Крылов П.С. Мониторинг рельефообразующих процессов с применением фотограмметрии и ГИС // Известия Самарского научного центра РАН. 2010. Т. 12 (33). № 1 (4). С. 1170-1176].

Dedkov A.P. (Ed.), 1990. Gully Erosion in the Eastern Part of the Russian Plain. Publishing House of Kazan State University, Kazan, 141 p. (in Russian) [Овражная эрозия востока Русской равнины / Под ред. А.П. Дедкова. Казань: Изд-во Казанского университета, 1990. 141 с.].

Dedkov A.P., Mozzherin V.I., Safina G.R., 1997. Modern variability of erosion of steppe and forest-steppe zones of the East European Plain. Geomorphology 2, 39-43 (in Russian) [Дедков А.П., Мозжерин В.И., Сафина Г.Р. Современная изменчивость эрозии в степной и лесостепной зонах Восточно-Европейской равнины // Геоморфология. 1997. № 2. C. 39-43].

Filatov A.V., 2006. Detection of surface displacements in the zone of intensive oil production by radar interferometry methods. Bulletin of the Yugra State University 4, 103-109 (in Russian) [Филатов А.В. Обнаружение подвижек земной поверхности в зоне интенсивной нефтедобычи методами радарной интерферометрии // Вестник Югорского государственного университета. 2006. № 4. С. 103-109].

Filatov V.F., 1967. Application of the morphometric method in the territory of the Vilyui syncline. In: Issues of Morphometry. Publishing House of Saratov University, Saratov, Issue 2, p. 261-272 (in Russian) [Филатов В.Ф. Применение морфометрического метода на территории Вилюйской синеклизы // Вопросы морфометрии. Саратов: Издательство Саратовского университета, 1967. Вып. 2. С. 261-272].

Filosofov V.P., 1975. Fundamentals of the Morphometric Method of Tectonic Structures Prospecting. Publishing House of Saratov University, Saratov, 232 р. (in Russian) [Философов В.П. Основы морфометрического метода поисков тектонических структур. Саратов: Издательство Саратовского университета, 1975. 232 с.].

Keay-Bright J., Boardma J., 2009. Evidence from field-based studies of rates of soil erosion on degraded land in the central Karoo, South Africa. Geomorphology 103 (3), 455-465. http://dx.doi.org/10.1016/j.geomorph.2008.07.011.

Krasny L.I., Petrov O.V., Blyuman B.A., 2004. The Earth Planet. Encyclopedic Reference Book. Volume: Tectonics and Geodynamics. VSEGEI Publishing House, St. Petersburg, 652 p. (in Russian) [Красный Л.И., Петров О.В., Блюман Б.А. Планета Земля. Энциклопедический справочник. Том «Тектоника и геодинамика». СПб.: Издательство ВСЕГЕИ, 2004. 652 с.].

Kuz'min Yu.O., 1999. Recent Geodynamics and Evaluation of Geodynamic Risk at Use of Subsoil Resources. Agentstvo Ekonomicheskikh Novostei, Moscow, 220 p. (in Russion) [Кузьмин Ю.О. Современная геодинамика и оценка геодинамического риска при недропользовании. М.: АЭН, 1999. 220 с.]

Kuz'min Yu.O., Zhukov V.S., 2004. Recent Geodynamics and Variations of Physical Properties of Rocks. Publishing House of Moscow State Mining University, Moscow, 262 p. (in Russian) [Кузьмин Ю.О., Жуков В.С. Современная геодинамика и вариации физических свойств горных пород. М.: Издательство Московского государственного горного университета, 2004. 262 с.].

Lastochkin A.N., 1971. About neotectonic criteria of oil-and-gas-bearing capacities. Bulletin of the All-Union Geographic Society 3, 201-215 (in Russian) [Ласточкин А.Н. О неотектонических критериях нефтегазоносности. Известия Всесоюзного географического общества. 1971. № 3. С. 201-215].

Nikonov A.A., 2006. The Recent Crustal Movements. KomKniga, Moscow, Edition 2, 181 p. (in Russian) [Никонов А.А. Современные движения земной коры. М.: КомКнига, 2006. Изд. 2-е. 181 с.]

Parkner T., Page M.J., Marutani T., Trustrum N.A., 2006. Development and controlling factors of gullies and gully complexes, East Coast, New Zealand. Earth Surface Processes and Landforms 32 (2), 187-199. http://dx.doi.org/10.1002/ esp.1321.

Petrov O.V., 2010. Geological Dictionary (in Three Volumes). Revised Edition 3. VSEGEI Publishing House, St. Petersburg, Vol. 1, 432 p. (in Russian) [Петров О.В. Геологический словарь. В трех томах. Издание третье, перераб. и доп. СПб.: Издательство ВСЕГЕИ, 2010. Т. 1. 432 с.].

Serebrennikova I.A., Butakov G.P., Yusupova V.V., Denmukhametov R.R., Butakov V.G., Machina O.V., 1999. Velocities of planned displacements of river channels and ecological assessment of the territory of the southern Tatarstan. Publishing House of Bashkir State University, Ufa, 241 p. (in Russian) [Серебренникова И.А., Бутаков Г.П., Юсупова В.В., Денмухаметов P.P., Бутаков В.Г., Мачина О.В. Скорости плановых смещений русел рек и экологическая оценка территории юга Татарстана. Уфа: Издательство Башкирского государственного университета, 1999. 241 с.].

Solutions. Monitoring. Emergencies. 2012. Available from: http://www.geokosmos.ru/solutions/monitoring/adversity (last accessed 18.09.2013).

Tratsevskaya E.Yu., Abramovich O.K., 2008. The current dynamic state of the geological environment of the city of Gomel 
and its impact on geotechnical conditions. Litasfera 29 (3), 110-117 (in Russian) [Трацевская Е.Ю., Абрамович О.К. Современное динамическое состояние геологической среды г. Гомеля и его влияние на инженерно-геологические условия // Літасфера. 2008. Т. 29. № 3. С.110-117].

Trifonov V.G., 1999. Neotectonics of Eurasia. Nauchny Mir, Moscow, 252 p. (in Russian) [Трифонов В.Г. Неотектоника Евразии. М.: Научный мир, 1999. 254 с.].

Zayonts V.N., Filatov V.F. Filosofov V.P. 1967. Experiences of prospecting for salt-dome structures by the morphometric method in the Vilyui and Caspian synclines and the Preduralsky marginal trough. In: Issues of Morphometry. Publishing House of Saratov University, Saratov, Issue 2, p. 279-286 (in Russian) [Зайонц В.Н., Филатов В.Ф., Философов В.П. Опыт поисков солянокупольных структур морфометрическим методом в Вилюйской, Прикаспийской синеклизах и в Предуральском краевом прогибе // Вопросы морфометрии. Саратов: Издательство Саратовского университета, 1967. Вып. 2. С. 279-286].

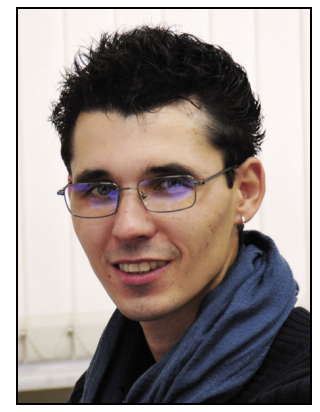

Нугманов Ильмир Искандарович, ассистент кафедры геофизики и геоинформационных технологий Казанский федеральный университет, Институт геологии и нефтегазовых технологий 420008, Казань, ул. Кремлевская, 18, Россия

Тел.: +7(919)6377201; $ه$ e-mail: Ilmir.Nugmanov@kpfu.ru

Nugmanov, Ilmir I., Assistant of Department of Geophysics and Geoinformation Technology Institute of Geology and Petroleum Technologies, Kazan Federal University 18 Kremlyovskaya street, Kazan 420008, Republic of Tatarstan, Russia Tel.: +7(919)6377201; $₫$ e-mail: Ilmir.Nugmanov@kpfu.ru

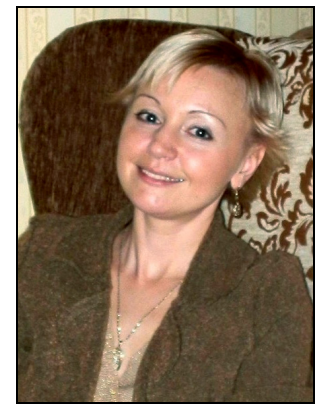

Нугманова Екатерина Владимировна, канд. геол.-мин. наук, старший преподаватель кафедры геофизики и геоинформационных технологий

Казанский федеральный университет, Институт геологии и нефтегазовых технологий 420008, Казань, ул. Кремлевская, 18, Россия

Тел.:+7(987)4167397; e-mail: eronina_ev@mail.ru

Nugmanova, Ekaterina V., Candidate of Geology and Mineralogy,

Senior Professor of Department of Geophysics and Geoinformation Technology

Institute of Geology and Petroleum Technologies, Kazan Federal University

18 Kremlyovskaya street, Kazan 420008, Republic of Tatarstan, Russia

Tel.: +7(987)4167397; e-mail: eronina_ev@mail.ru

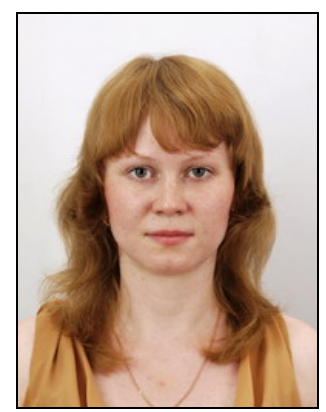

Лунева Ольга Викторовна, инженер кафедры геофизики и геоинформационных технологий Казанский федеральный университет, Институт геологии и нефтегазовых технологий 420008, Казань, ул. Кремлевская, 18, Россия

Тел.: +7(919)6907096; e-mail: olunjova@yandex.ru

Luneva, Olga V., Engineer of Department of Geophysics and Geoinformation Technology Institute of Geology and Petroleum Technologies, Kazan Federal University

18 Kremlyovskaya street, Kazan 420008, Republic of Tatarstan, Russia

Tel.: +7(919)6907096; e-mail: olunjova@yandex.ru

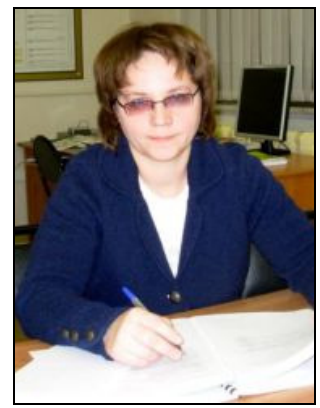

Чернова Инна Юрьевна, канд. геол.-мин. наук, доцент кафедры геофизики и геоинформационных технологий Казанский федеральный университет, Институт геологии и нефтегазовых технологий 420008, Казань, ул. Кремлевская, 18, Россия

Тел.: +7(987)2760805; e-mail: Inna.Chernova@kpfu.ru

Chernova, Inna Yu., Candidate of Geology and Mineralogy, Associated Professor

of Department of Geophysics and Geoinformation Technology

Institute of Geology and Petroleum Technologies, Kazan Federal University

18 Kremlyovskaya street, Kazan 420008, Republic of Tatarstan, Russia

Tel.: +7(987)2760805; e-mail: Inna.Chernova@kpfu.ru 